\title{
Long-term outcomes of cementless femoral stem revision with the Wagner cone prosthesis
}

\author{
Kyung-Soon Park, Sheng-Yu Jin, Jun-Hyuk Lim and Taek-Rim Yoon * (D)
}

\begin{abstract}
Background: The procedure of femoral stem revision is challenging, and bone conservation with less stress shielding is a mandatory effort in these cases. Although there are several reports of stem revision with stems designed for primary total hip arthroplasty (THA), there is no report on stem revision with the Wagner cone prosthesis.
\end{abstract}

Methods: Between 1996 and 2008, 41 hips of 41 consecutive patients were subjected to femoral revision THA using the Wagner cone prosthesis. The mean age during revision surgery was 56.1 years, and the mean follow-up period was 14.8 years. The clinical results were evaluated, and the femoral component was assessed radiologically.

Results: The results showed that the average period from the first operation to revision THA was 8.0 years. Additionally, the mean Harris hip score improved from 52 points preoperatively to 83 points at the final follow-up. All stems showed bone integration in the radiological evaluation. A subsidence of more than $5 \mathrm{~mm}$ was observed in 3 out of 28 (10.7\%) femoral stems. Two patients needed an acetabular revision for acetabular cup loosening during the follow-up period. Furthermore, one patient had recurrent dislocation and had to undergo revision surgery for soft tissue augmentation.

Conclusions: We achieved favorable clinical and radiological long-term outcomes in femoral stem revision using the Wagner cone prosthesis. This cementless femoral stem could be an option for femoral stem revision in cases with relatively good bone stock.

Keywords: Revision total hip arthroplasty, Cementless femoral stem, Wagner cone prosthesis, Stress shielding

\section{Background}

Due to the increasing life-expectancy and the increasing trend of performing total hip arthroplasty (THA) even in young individuals and physically active patients, the number of THAs has risen rapidly, and the revision and re-revision rates are expected to increase proportionally. It is expected that the proportion of revision THAs will increase by $137 \%$ between 2005 and 2030 [1].

\footnotetext{
* Correspondence: tryoon@naver.com

Department of Orthopedic Surgery, Center for Joint Disease, Chonnam National University Hwasun Hospital, 322 Seo Yang-Ro, Hwasun-Eup, Hwasun-Gun, Gwangju, Jeonnam 519-809, Republic of Korea
}

Revision after failure of femoral components may be technically demanding due to the loss of the periprosthetic bone stock. Moreover, multiple surgeries can result in significant bone and soft tissue deficits. The cemented prosthesis is not a good choice for femoral stem revision; Edward et al. [2] reported that the cemented revision stem showed a higher rate of radiographic failure as compared to the cementless stem in a 20-year follow-up.

Hence, cementless stem revision is the preferred choice in femoral stem revision. Different kinds of cementless stems can be chosen based on the femoral 
bone loss, such as a proximal porous-coated stem [3], cylindrical stem, extensively porous-coated stem [4], or tapered fluted stem [5].

However, a cementless femoral stem could result in stress shielding issues. Increased length of the femoral stem is associated with a high risk of stress shielding [6]. Alternatively, the use of modular revision stems allows the surgeon to customize each component according to the intraoperative needs, owing to the independent preparation of the proximal and distal femur to optimize the femoral fill and fit, thus avoiding stress shielding. However, even though the modular revision stems can provide more stable fixation, they are usually bulky, which could lead to host bone loss during surgery. Additionally, they are expensive and need technical surgical skills to perform the procedure perfectly for the benefit of the patient and improved functional outcomes.

The Wagner cone prosthesis (Zimmer-Biomet, Warsaw, IN, USA) was designed for use in primary THA. It has a tapered design to provide primary stability with 8 ribs, which ensure increased rotational stability. This prosthesis was introduced in 1995, and its design had been changed once in 2005 since then. Fundamentally, it is still used by many surgeons in THA. This stem can provide distal fixation. Even if the patient presents with a severe bone defect, such as septic hip or developmental dysplasia of hip sequelae, it provides favorable clinical outcomes.

There are several reports on various cementless primary THA stems used in femoral stem revision [5, 713], but not on the use of the Wagner cone prosthesis. This study aimed to evaluate the long-term clinical and radiographic outcomes of femoral stem revision using the Wagner cone prosthesis in femoral stem revision.

\section{Materials and methods}

This study evaluated 41 hips of 41 consecutive patients subjected to femoral revision THA by a single surgeon using the Wagner cone prosthesis through a posterolateral approach between 1996 and 2008. Among them, 8 patients were lost to follow-up of less than 10 years, and 5 patients died from other causes unrelated to THA. The remaining 28 patients were followed up for more than 10 years. The mean age of the patients during the revision surgery was 56.1 years, and the mean follow-up period was $14.8(10.1-20.9)$ years.

The causes of primary THA were osteonecrosis of the femoral head in 18 hips, osteoarthritis in 5 hips, femoral neck fracture in 3 hips, and rheumatoid arthritis in 2 hips. Among the 28 hips, an acetabular cup revision was performed simultaneously in 14 hips, isolated stem revision in 9 hips, and a liner exchange at the time of stem revision in 5 hips. The initial femoral stems were listed as Autophor (Osteo AG, Selzach, Switzerland) in 10 hips, PFC
(Johnson \& Johnson, Raynham, MA, USA) in 6 hips, CLS (Zimmer, Winterthur, Switzerland) in 6 hips, and other cemented stems in the remaining 6 hips (Table 1).

All patients were evaluated clinically and radiologically. The clinical results were graded using the Harris hip scores (HHS) [14]. The radiographic evaluation was performed by comparing the patients' immediate postoperative radiographs and last follow-up radiographs. In order to evaluate the femoral component, the proximal aspect of the femur was divided into 7 zones, as described by Gruen et al. [15]. The radiolucent lines observed at the bone-implant interfaces were evaluated and measured on both the anteroposterior and lateral radiographs of the proximal aspect of the femur. Additionally, a migration analysis was performed by measuring the femoral component vertical subsidence, as described by Callaghan et al. [16]. The femoral component vertical subsidence was defined as a change in the distance from the landmark of the femoral component to the most proximal point of the greater trochanter. Generally, a difference of $5 \mathrm{~mm}$ or more in the vertical direction between the immediate postoperative and follow-up measurements indicated the presence of vertical subsidence. All the radiographs were assessed for loosening, stable fibrous fixation, and bone ingrowth

Table 1 Demographic details and preoperative status of patients

\begin{tabular}{|c|c|}
\hline Demographic data & \\
\hline Male/female & $21 / 7$ \\
\hline Age (years) & 56.1 (range, 40-76) \\
\hline F/U duration (years) & 14.8 (range, 10.1-20.9) \\
\hline Mean period from 1st to revision (years) & 8.0 (range, 4.2-9.2) \\
\hline \multicolumn{2}{|l|}{ Indication for THA } \\
\hline \multicolumn{2}{|l|}{ Osteonecrosis of the femoral head } \\
\hline \multicolumn{2}{|l|}{ Osteoarthritis } \\
\hline \multicolumn{2}{|l|}{ Femoral neck fracture } \\
\hline \multicolumn{2}{|l|}{ Rheumatoid arthritis } \\
\hline \multicolumn{2}{|l|}{ Procedure for revision THA } \\
\hline Stem and cup revision & 14 \\
\hline Isolated stem revision and liner change & 9 \\
\hline Isolated stem revision & 5 \\
\hline \multicolumn{2}{|l|}{ Femoral stems before revision } \\
\hline Autophor (Osteo AG, Selzach, Switzerland) & 10 \\
\hline PFC (Johnson \& Johnson, Raynham, MA, USA) & 6 \\
\hline CLS (Zimmer, Winterthur, Switzerland) & 6 \\
\hline Other cemented stems & 6 \\
\hline
\end{tabular}

THA total hip arthroplasty 
around the porous proximal sleeve of the prosthesis using the criteria described by Engh et al. [17]. The classification system by Paprosky et al. [18] was used to evaluate the preoperative bone loss, which is based on the location and extent of the femoral bone loss. The heterotopic bone formation was graded using the classification system by Brooker et al. [19]. The degree of stress shielding was assessed using Engh's classification [20] by comparing the immediate postoperative radiographs and the last follow-up radiographs. Moreover, evaluations were performed at each follow-up to identify any complications.

The data were analyzed for statistical significance using the chi-square test for categorical variables and the student's $t$ test for continuous variables; $P$ values $\leq 0.05$ were considered statistically significant. All statistical analyses were performed using the Statistical Product and Service Solutions software version 25.0 (SPSS, Chicago, IL). We performed a 10-year and expected 15year survival analysis using the Kaplan-Meier technique with $95 \%$ confidence intervals.

\section{Results}

The average period from the first operation to revision THA was 8.0 years, and component aseptic loosening was an indication for surgery. Based on the Paprosky classification of femoral bone loss, there were 10 hips of type IIa, 7 hips of type IIb, 8 hips of type IIc, 2 hips of type IIIa, and 1 hip of type IIIb (Table 2).

The stem sizes of the Wagner cone prosthesis varied between 16 and 23. For the femoral bone loss, morselized allograft bone grafting was performed in 11 hips of types IIc, IIIa, or IIIb of the Paprosky classification. Additionally, for the prevention of femoral fracture during stem insertion, prophylactic femoral wiring was performed in 8 hips.

The mean HHS improved from 52 (range, 36-62) preoperatively to $83(67-98)$ at the final follow-up. It was noted that there were 13 patients with excellent rating, 10 with good rating, and 4 with fair rating as per the condition results. Only one patient underwent rerevision surgery for acetabular loosening and showed poor results.

All 28 (100\%) femoral stems showed bone integration radiologically, and 3 of 28 (10.7\%) femoral stems showed subsidence of more than $5 \mathrm{~mm}$. Partial resorption of the calcar femoris with signs of grade I stress shielding was observed in 5 hips (17.9\%). Bone resorption in the proximal portion of the femur (Gruen zones 1 and 7 ), regarded as grade II stress shielding, occurred in 2 hips (7.1\%) (Fig. 1). There was no sign of stress shielding in the remaining 21 hips (75\%) (Table 2).

Two patients needed acetabular cup revision due to acetabular aseptic loosening during the follow-up period.
Table 2 Radiographical results

\begin{tabular}{|c|c|}
\hline Parameters & Number of hips (\%) \\
\hline \multicolumn{2}{|c|}{ Preoperative femoral bone defect (Paprosky classification) } \\
\hline Ila & $10(35.7)$ \\
\hline$\| \mathrm{b}$ & $7(25.0)$ \\
\hline Ilc & $8(28.5)$ \\
\hline Illa & $2(7.1)$ \\
\hline$\| l l b$ & $1(3.6)$ \\
\hline IIIC & $0(0)$ \\
\hline Vertical subsidence & Average $1.67 \mathrm{~mm}(0 \sim 10 \mathrm{~mm})$ \\
\hline $0-3 \mathrm{~mm}$ & $19(67.8)$ \\
\hline 3-5 mm & $6(21.4)$ \\
\hline$>5 \mathrm{~mm}$ & $3(10.7)$ \\
\hline \multicolumn{2}{|l|}{ Stability by Engh method } \\
\hline Stable osteointegration & $26(92.8)$ \\
\hline Stable fibrous fixation & $1(3.5)$ \\
\hline Unstable fibrous fixation & $1(3.5)$ \\
\hline \multicolumn{2}{|c|}{ Radiolucentline (Gruen zone) } \\
\hline । & $11(39.2)$ \\
\hline$\|$ & $3(10.7)$ \\
\hline III & $0(0)$ \\
\hline IV & $0(0)$ \\
\hline V & $0(0)$ \\
\hline $\mathrm{Vl}$ & $2(7.1)$ \\
\hline VII & $7(25.0)$ \\
\hline \multicolumn{2}{|c|}{ Heterotopic bone formation } \\
\hline Grade I & $2(7.1)$ \\
\hline Grade II & $2(7.1)$ \\
\hline \multicolumn{2}{|l|}{ Stress shielding } \\
\hline Grade I & $5(17.9)$ \\
\hline Grade II & $2(7.1)$ \\
\hline Grade III & $0(0)$ \\
\hline
\end{tabular}

One patient complained of anterior thigh pain, and one patient had recurrent dislocation and underwent revision surgery for soft tissue augmentation. Additionally, one patient underwent internal fixation for the nontraumatic fracture of the greater trochanter, which was detected during the follow-up. There were no cases presenting periprosthetic fracture, infection, additional stem revision, deep vein thrombosis, or neurovascular injury.

Overall, the reoperation rate of THA was 14\% (4 out of 28 hips), and $100 \%$ patients ( 28 out of 28 hips) survived the femoral stem procedure. The overall survival rate with the endpoint of any revision was $92.9 \%$ (95\% confidence interval, 76.5-99.1\%) at the 10-year followup. Only for the stem as the endpoint of femoral stem revision, a $100 \%$ survival rate was noted. The overall expected 15-year survival rate with the endpoint of any 

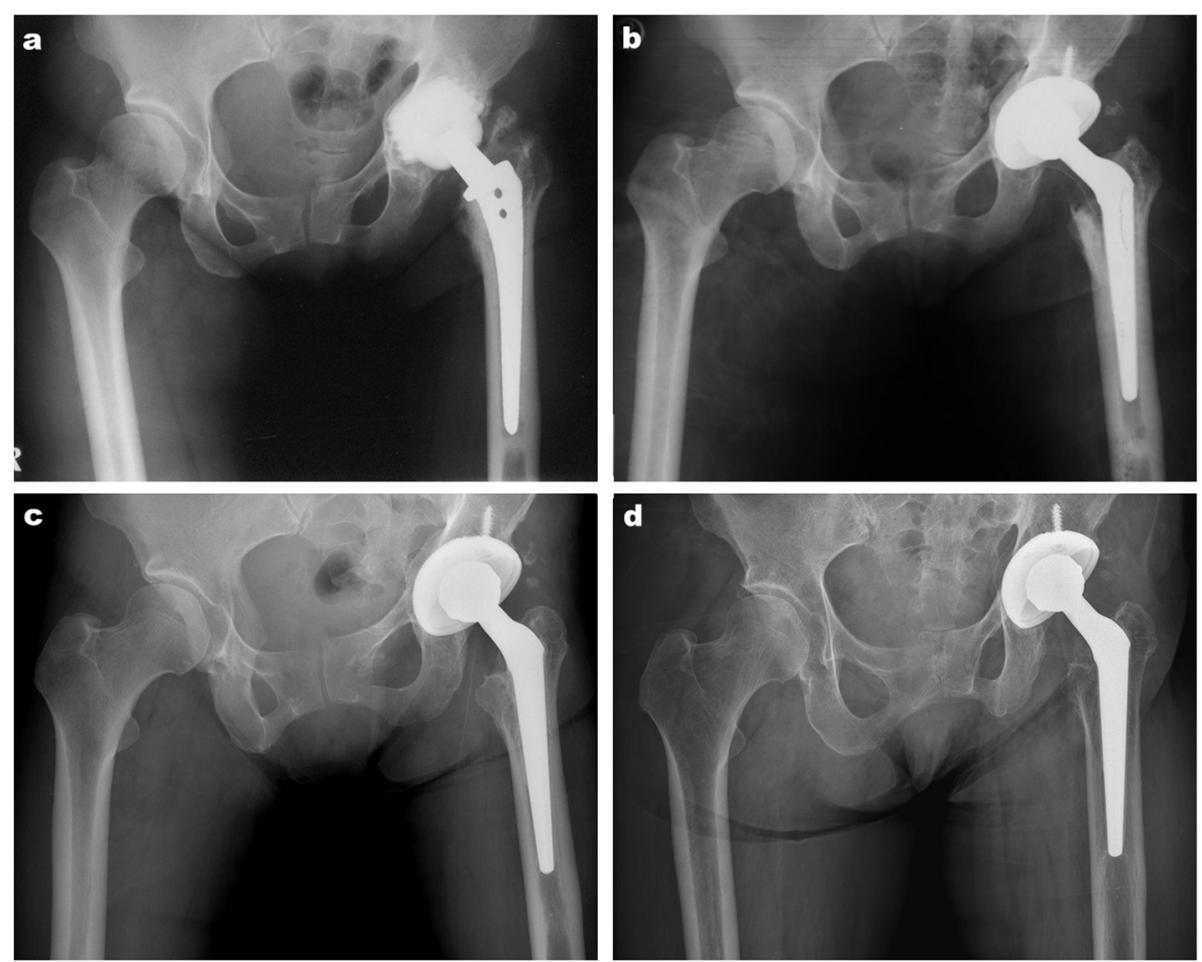

Fig. 1 a Preoperative radiograph of a 57-year-old woman with aseptic loosening of the Autophor femoral stem. b Immediate postoperative radiograph of the left hip: revision was performed using the Wagner cone stem and cementless acetabular cup. c Anteroposterior radiographic view of the left hip 3 years after the revision total hip arthroplasty (THA). $\mathbf{d}$ Anteroposterior radiographic view of the left hip 20 years after the THA shows grade II stress shielding in Gruen zones 1 and 7

revision was $83.4 \%$ (95\% confidence interval, $67.3-96.0 \%$ ) and that only for the femoral stem was $100 \%$ (Fig. 2).

\section{Discussion}

This study evaluated the midterm outcome of the Wagner cone prosthesis used in femoral revision surgery. Until now, there were no reports on the outcomes of the cementless stem, which was developed for primary THA and used in revision THA. Severe proximal femoral bone loss has been one of the challenging obstacles in successful revision THA. According to the results in this study, the use of the Wagner cone prosthesis could be a reliable treatment strategy in revision THA to achieve satisfactory long-term radiographic and clinical outcomes. This strategy can preserve the bone stock as well as prevent the stress shielding effect in patients undergoing this procedure.

Considering the poor initial outcomes of a cemented stem in revision surgery, a cementless femoral stem is the recommended choice in these cases. The cementless revision stems available in the commercial market are exemplified by the Wagner conical long stem, Link MP, or Zimmer modular stem with various designs including proximal porous-coated, extensively porous-coated, cylindrical, and tapered fluted. All of these stems are longer and fully surface treated with porous coating or grit blasting. These stems can provide an initial firm fixation in the distal portion in various bone defects, especially at the location of a proximal bone defect. However, for the fixation of these stems, more reaming as provided with a long reamer is considered mandatory, meaning that there is a high chance of more pronounced femoral bone loss in this case during revision surgery. Moreover, there is reportedly more proximal stress shielding and more thigh pain associated with this implant [20]. This situation becomes more difficult if the implant is infected or if it fails, as there would be no option for further femoral revision surgery.

The Wagner cone prosthesis is designed for primary THA, especially in patients with femurs characterized with a slim and rather cylindrical configuration and exhibiting a deformation of the intramedullary bony scarring of the proximal end of the femur after previous osteotomies [21, 22]. The Wagner cone prosthesis is fully surface treated with grit blasting that provides and encourages good bone ongrowth in the future. The cone shape design provides distal fixation of the stem, and the 8 ribs provide rotational stability. The stem sizes vary from 13 to 23 with $1 \mathrm{~mm}$ increasing thickness that can be used in femurs exhibiting a deformity or a narrow 


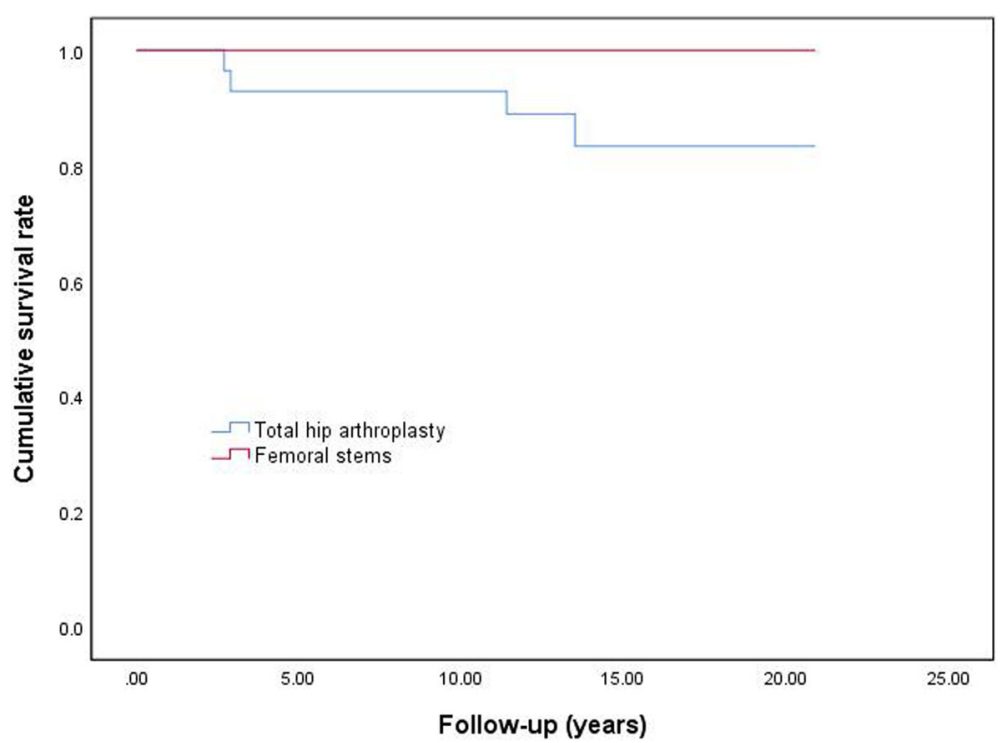

Fig. 2 Kaplan-Meier survival curves of survivorship with the endpoint of any revision and only femoral stem revision

medullary canal. These stem designs can overcome the proximal bone defects in such cases. The large proximal femoral bone defects can be reduced by using a thicker stem after reaming with a round reamer. Even after the process of stem fixation, if there are bone defects that create gaps between the femoral stem and proximal femur, the defect can be filled with morselized bone grafts.

Patients with Paprosky type IIIB or type IV femoral bone loss, who underwent treatment with the extensively porous-coated femoral components, have shown a high rate of mechanical failure [2]. Even though an extensively porous-coated stem for revision THA is reported to have a more than $95 \%$ survival rate after a 10 -year follow-up, the proximal bone deficiency increased the failure rate in these cases. Furthermore, revision THA in patients with extensive proximal femoral bone loss using a tapered fluted modular femoral component showed a relatively high rate of diaphyseal stress shielding (22\%) [23]. In this study, most patients showed satisfactory radiographic and clinical outcomes. Although 3 patients showed subsidence of more than $5 \mathrm{~mm}$, there were no other cases of instability noted during the follow-up after adaptation of the prosthesis to the medullary canal.

With respect to the clinical outcomes, $78.6 \%$ of the patients with good or excellent HHS reported minimal or no pain with this process. Thus, considering that thigh pain is a predominant symptom following uncemented femoral revision, it is encouraging that only one patient reported postoperative thigh pain in the latest follow-up. In this study, the total complication rate was $17.8 \%$ (Table 3), but the overall expected 15-year survival rate with the endpoint with femoral stem failure was $100 \%$.
As compared with previous studies [24-27], we believe that the Wagner cone prosthesis is an acceptable option for revision cases.

To our knowledge, this study is the first to report the long-term outcomes of the Wagner cone prosthesis indicated in revision THA. Compared to revision THA using a longer revision stem, the use of the Wagner cone prosthesis is more advantageous as it has positive patient outcomes in terms of less stress shielding, better preservation of bone stock, less damage to the existing bony structure during revision THA, and low monetary cost. In complicated cases noted frequently, such as those with less bone stock in revision THA, special attention is required during the implant size planning stage. The findings of this study suggest that the Wagner cone prosthesis shows axial and rotational stability when its use is accompanied by adequate bone grafting. However, the implant size should be selected cautiously beforehand, considering the amount of bone defect and existence of compromised bone quality. On the planning template, it is recommended that the contour of the stem should overlap the inner contour of the cortex in the middle third portion of the stem by $1 \mathrm{~mm}$.

In this study, 5 cemented stems with loosening were subjected to revision surgery using the Wagner cone prosthesis. For the revision from a cemented stem to a cementless stem, cement removal is mandatory, and the most challenging part is the removal of the distal part of the cement. There were 2 hips among 5 hips with remaining cement in the distal part and a cement plug. Because the Wagner cone prosthesis is fixed more proximally to this remnant cement, it was unnecessary to remove the well-fixed distal cement. The other 3 hips 
Table 3 Comparison with other results of femoral revision using femoral stems for primary THA

\begin{tabular}{llllll}
\hline Years & $\mathbf{1 9 9 4}[\mathbf{2 5}]$ & $\mathbf{1 9 9 7}[\mathbf{2 6}]$ & $\mathbf{1 9 9 5}[\mathbf{2 7}]$ & $\mathbf{2 0 0 1}[\mathbf{2 8}]$ & \\
\hline Authors & Lawrence & Krishnamurthy & Moreland & Moreland & Present study \\
No. of case & 83 & 297 & 175 & 137 & 28 \\
F/U duration (years) & $9(5 \sim 13)$ & $8.3(5 \sim 13)$ & 5 & $9.3(5 \sim 16)$ & 7.6 \\
Stem design & AML stem & AML stem & AML stem & AML stem & Wagner cone prosthesis \\
Total complication rate & $24(29 \%)$ & $5.7 \%(4 \%)$ & $19(10 \%)$ & $24(18 \%)$ & $5(17.8 \%)$ \\
Survival & $90 \%$ & $98.3 \%$ & $96 \%$ & $92.7 \%$ & $100 \%$ \\
\hline
\end{tabular}

showed cement loosening even in the distal part of the cemented stem, which was easy to remove (Fig. 3).

It is known that the incidence of femoral osteolysis after cementless hip arthroplasty increases with time and may progress rapidly. Generally, in femoral stem revision with fully porous-coated implants, continued follow-up and prevention of further osteolysis are essential for optimal patient health outcomes. Therefore, the Wagner cone prosthesis, which guarantees less bone loss during and after surgery, is an appropriate candidate for use in revision THA.

In our series, most patients were relatively young and the bone stock quality was relatively good, thus ensuring favorable outcomes with the Wagner cone prosthesis.
However, in the elderly patients and those with poor bone quality, the Wagner self-locking (SL) stem (long length stem) may be a better choice. Zang et al. [28] reported a study of 38 patients (40 hips) who underwent revision THA with the Wagner SL stem. At the last follow-up, incorporation of the grafted bone was observed in 28 hips (70.0\%). Sandiford et al. [29] found that the Wagner SL stem could achieve high levels of function with a low revision risk.

Our study has some limitations. First, there was no control group to compare the functional outcomes and clinical outcomes. Second, the sample size was relatively limited. However, as per our knowledge, this report is the first to evaluate the clinical and radiological

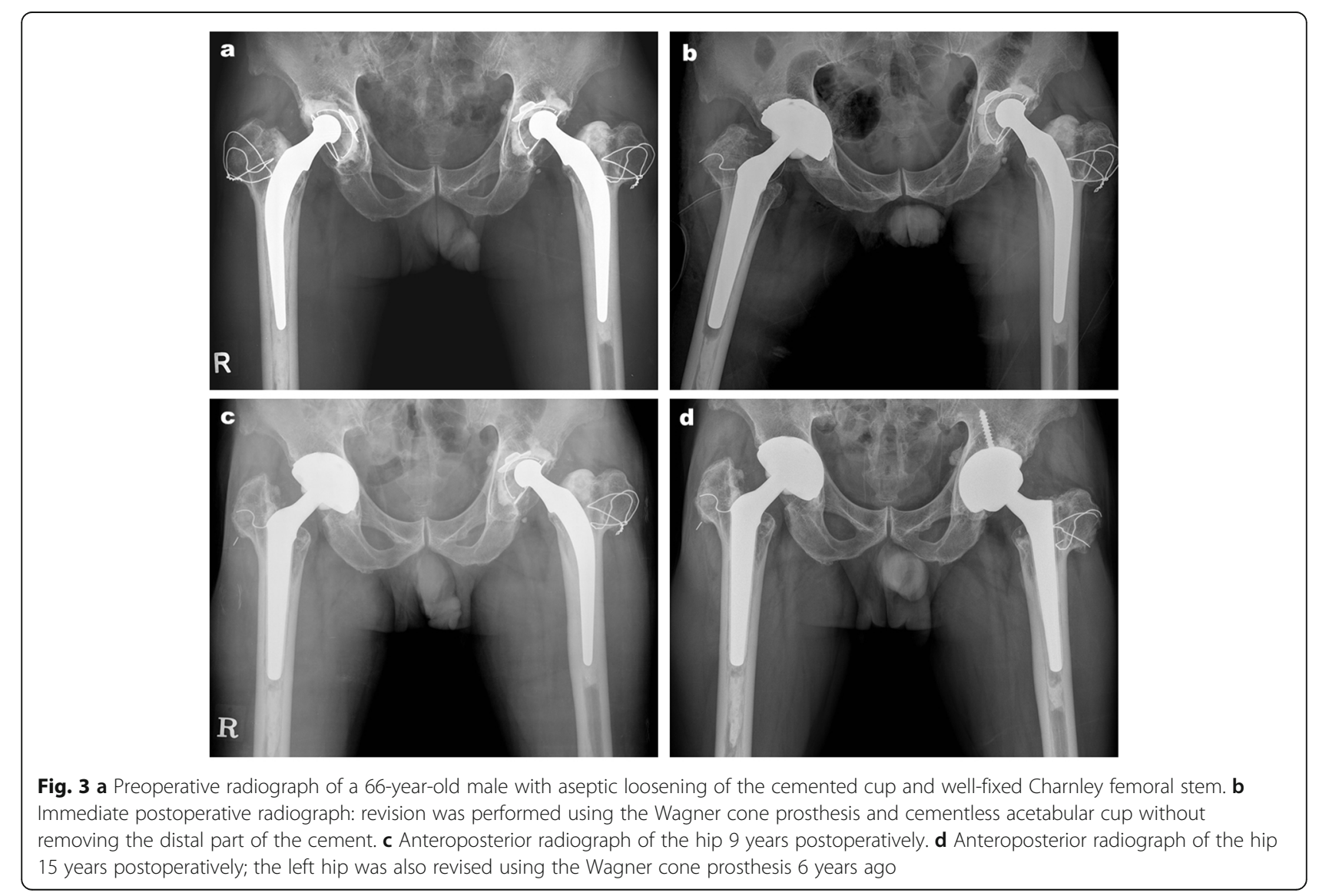


outcomes of the Wagner cone prosthesis in femoral stem revision.

\section{Conclusions}

In conclusion, we achieved favorable clinical and radiological long-term outcomes in femoral stem revisions using the Wagner cone prosthesis. This cementless femoral stem is a good option for femoral stem revision in cases with relatively good bone stock.

\section{Abbreviations}

THA: Total hip arthroplasty; HHS: Harris hip score; SL: Self-locking

\section{Acknowledgements}

Not applicable

\section{Authors' contributions}

KSP conceived the study, participated in the design of this study, and wrote the manuscript. SYJ and JHL analyzed the data. TRY provided critical review and substantially revised the manuscript. The authors read and approved the final manuscript.

\section{Funding}

The authors have no funding sources to report.

\section{Availability of data and materials}

The data sets supporting the results of this article are included within the article and its additional files. The datasets will be available from the corresponding author on reasonable request.

\section{Declarations}

\section{Ethics approval and consent to participate}

This study was approved by the Institutional Review Board of the Chonnam National University Hwasun Hospital. Written informed consent was obtained from all patients.

\section{Consent for publication}

Not applicable

\section{Competing interests}

The authors declare that they have no conflict of interests.

Received: 8 March 2021 Accepted: 4 May 2021

Published online: 11 June 2021

References

1. Kurtz S, Ong K, Lau E, Mowat F, Halpern M. Projections of primary and revision hip and knee arthroplasty in the United States from 2005 to 2030. Bone Joint Surg Am. 2007;89(4):780-5. https://doi.org/10.2106/jbjs.f.00222.

2. Desai RR, Malkani AL, Hitt KD, Jaffe FF, Schurman JR 2nd, Shen J. Revision total hip arthroplasty using a modular femoral implant in Paprosky type III and IV femoral bone loss. J Arthroplasty. 2012;27(8):1492-1498.e1491. https://doi.org/10.1016/j.arth.2012.03.039.

3. Viste A, Perry KI, Taunton MJ, Hanssen AD, Abdel MP. Proximal femoral replacement in contemporary revision total hip arthroplasty for severe femoral bone loss: a review of outcomes. Bone Joint J. 2017;99-b(3):325-9. https://doi.org/10.1302/0301-620x.99b3.bjj-2016-0822.r1

4. Ahmet $S$, İsmet $K$, Mehmet $E$, Eren $Y$, Remzi T, Önder $Y$. Midterm results of the cylindrical fully porous-coated uncemented femoral stem in revision patients with Paprosky I-IIIA femoral defects. J Orthop Surg (Hong Kong). 2018;26(2):2309499018783906. https://doi.org/10.1177/2309499018783906.

5. Huang $Y$, Zhou $Y$, Shao $H, G u$ J, Tang $H$, Tang Q. What is the difference between modular and nonmodular tapered fluted titanium stems in revision total hip arthroplasty. J Arthroplasty. 2017:32(10):3108-13. https:// doi.org/10.1016/j.arth.2017.05.021

6. Small SR, Hensley SE, Cook PL, Stevens RA, Rogge RD, Meding JB, et al. Characterization of femoral component initial stability and cortical strain in a reduced stem-length design. J Arthroplasty. 2017;32(2):601-9. https://doi. org/10.1016/j.arth.2016.07.033.

7. Thorey F, Lerch M, Kiel H, von Lewinski G, Stukenborg-Colsman C, Windhagen $\mathrm{H}$. Revision total hip arthroplasty with an uncemented primary stem in 79 patients. Arch Orthop Trauma Surg. 2008;128(7):673-8. https:// doi.org/10.1007/s00402-007-0462-0.

8. Hoskins WT, Bingham RJ, Lorimer M, de Steiger RN. The effect of size for a hydroxyapatite-coated cementless implant on component revision in total hip arthroplasty: an analysis of 41,265 stems. J Arthroplasty. 2020;35(4):10748. https://doi.org/10.1016/j.arth.2019.10.060.

9. Yan SG, Woiczinski M, Schmidutz TF, Weber P, Paulus AC, Steinbrück A, et al. Can the metaphyseal anchored Metha short stem safely be revised with a standard CLS stem? A biomechanical analysis. Int Orthop. 2017:41(12):24717. https://doi.org/10.1007/s00264-017-3497-z

10. Wang J, Dai WL, Lin ZM, Shi ZJ. Revision total hip arthroplasty in patients with femoral bone loss using tapered rectangular femoral stem: a minimum 10 years' follow-up. Hip Int. 2020;30(5):622-8. https://doi.org/10.1177/112 0700019859809

11. Wood TJ, Alzahrani M, Marsh D, Somerville LE, Vasarhelyi EM, Lanting BA. Use of the Corail stem for revision total hip arthroplasty: evaluation of clinical outcomes and cost. Can J Surg. 2019;62(2):78-82. https://doi.org/10.1 503/cjs.002318.

12. Kelly SJ, Incavo SJ, Beynnon B. The use of a hydroxyapatite-coated primary stem in revision total hip arthroplasty. J Arthroplasty. 2006;21(1):64-71. https://doi.org/10.1016/j.arth.2004.11.013.

13. Gastaud O, Cambas PM, Tabutin J. Femoral revision with a primary cementless stem. Orthop Traumatol Surg Res. 2016;102(2):149-53. https:// doi.org/10.1016/j.otsr.2015.12.014

14. Mahomed NN, Arndt DC, McGrory BJ, Harris WH. The Harris hip score: comparison of patient self-report with surgeon assessment. J Arthroplasty. 2001;16(5):575-80. https://doi.org/10.1054/arth.2001.23716.

15. Gruen TA, McNeice GM, Amstutz HC. "Modes of failure" of cemented stemtype femoral components: a radiographic analysis of loosening. Clin Orthop Relat Res. 1979;141:17-27.

16. Callaghan JJ, Salvati EA, Pellicci PM, Wilson PD Jr, Ranawat CS. Results of revision for mechanical failure after cemented total hip replacement, 1979 to 1982. A two to five-year follow-up. J Bone Joint Surg Am. 1985;67(7): 1074-85.

17. Engh CA, Massin P, Suthers KE. Roentgenographic assessment of the biologic fixation of porous-surfaced femoral components. Clin Orthop Relat Res. 1990;257:107-28.

18. Paprosky WG, Greidanus NV, Antoniou J. Minimum 10-year-results of extensively porous-coated stems in revision hip arthroplasty. Clin Orthop Relat Res. 1999;369:230-42. https://doi.org/10.1097/00003086-19991200000024.

19. Brooker AF, Bowerman JW, Robinson RA, Riley LH Jr. Ectopic ossification following total hip replacement. Incidence and a method of classification. J Bone Joint Surg Am. 1973;55(8):1629-32. https://doi.org/10.2106/00004623-1 97355080-00006.

20. Engh CA Jr, McAuley JP, Sychterz CJ, Sacco ME, Engh CA Sr. The accuracy and reproducibility of radiographic assessment of stress-shielding. A postmortem analysis. J Bone Joint Surg Am. 2000;82(10):1414-20. https:// doi.org/10.2106/00004623-200010000-00007.

21. Zhang Q, Goodman SB, Maloney WJ, Huddleston JI 3rd. Can a conical implant successfully address complex anatomy in primary THA? Radiographs and hip scores at early followup. Clin Orthop Relat Res. 2016; 474(2):459-64. https://doi.org/10.1007/s11999-015-4480-x.

22. Parry MC, Vioreanu MH, Garbuz DS, Masri BA, Duncan CP. The Wagner cone stem for the management of the challenging femur in primary hip arthroplasty. J Arthroplasty. 2016;31(8):1767-72. https://doi.org/10.1016/j.a rth.2016.02.007.

23. Amanatullah DF, Howard JL, Siman H, Trousdale RT, Mabry TM, Berry DJ. Revision total hip arthroplasty in patients with extensive proximal femoral bone loss using a fluted tapered modular femoral component. Bone Joint J. 2015;97-b(3):312-7. https://doi.org/10.1302/0301-620x.97b3.34684

24. Lawrence JM, Engh CA, Macalino GE, Lauro GR. Outcome of revision hip arthroplasty done without cement. J Bone Joint Surg Am. 1994;76(7):96573. https://doi.org/10.2106/00004623-199407000-00002.

25. Krishnamurthy AB, MacDonald SJ, Paprosky WG. 5- to 13-year follow-up study on cementless femoral components in revision surgery. J Arthroplasty. 1997;12(8):839-47. https://doi.org/10.1016/s0883-5403(97)90152-2. 
26. Moreland JR, Bernstein ML. Femoral revision hip arthroplasty with uncemented, porous-coated stems. Clin Orthop Relat Res. 1995;319:141-50.

27. Moreland JR, Moreno MA. Cementless femoral revision arthroplasty of the hip: minimum 5 years followup. Clin Orthop Relat Res. 2001;393:194-201. https://doi.org/10.1097/00003086-200112000-00022.

28. Zang J, Uchiyama K, Moriya M, Fukushima K, Takahira N, Takaso M. Longterm outcomes of Wagner self-locking stem with bone allograft for Paprosky type II and III bone defects in revision total hip arthroplasty: a mean 15.7-year follow-up. J Orthop Surg. 2019;27(2):2309499019854156. https://doi.org/10.1177/2309499019854156.

29. Sandiford NA, Garbuz DS, Masri BA, Duncan CP. Nonmodular tapered fluted titanium stems osseointegrate reliably at short term in revision THAs. Clin Orthop Relat Res. 2017;475(1):186-92. https://doi.org/10.1007/s11999-0165091-X.

\section{Publisher's Note}

Springer Nature remains neutral with regard to jurisdictional claims in published maps and institutional affiliations.

Ready to submit your research? Choose BMC and benefit from:

- fast, convenient online submission

- thorough peer review by experienced researchers in your field

- rapid publication on acceptance

- support for research data, including large and complex data types

- gold Open Access which fosters wider collaboration and increased citations

- maximum visibility for your research: over $100 \mathrm{M}$ website views per year

At BMC, research is always in progress.

Learn more biomedcentral.com/submissions 